\title{
Seed Dormancy and Effect of Salinity on Germination of Citrullus Colocynthis
}

\author{
Kiran Menon, Aswathy Preetha Jayakumar, Mohammad Shahid, Neeru Sood, and Nanduri K. Rao
}

\begin{abstract}
Citrullus colocynthis has been garnering interest in recent times as a potential biodiesel feedstock crop due to its high seed oil content (up to $50 \%$ ). There have been reports of seed dormancy in this crop, which can be a deterrent to its commercial cultivation. In this study, different pre-treatment methods to break seed dormancy were compared. Citrullus colocynthis is drought resistant, as established from the fact that it grows as a weed in arid and semi-arid lands. The tolerance of this crop to different levels of salinity during germination in vitro was investigated. An effective treatment to break seed dormancy was identified and locally collected germplasm was screened for salinity tolerance.
\end{abstract}

Index Terms-Biodiesel feedstock, salinity tolerance, germination efficiency.

\section{INTRODUCTION}

Citrullus colocynthis (L.) Schrad., also known as desert gourd, Handhal and Thumba (in Arabic), is a member of the Cucurbitaceae family, known for its high seed protein (35\%) and oil $(50 \%)$ content [1]. It grows in the wild in many regions of the world such as India, the Middle East. According to some reports this plant is listed as a medicinal halophyte that grows in coastal areas with salty or brackish waters [2]. A study of colocynth in Saudi Arabia indicates that it compensates for the high temperatures in deserts by an increased transcription rate which cools the leaf temperature to less than ambient temperature to prevent tissue damage. The disadvantage of this is that the plant is a water-spender and its distribution is determined by the level of the underground water table, which the tap root needs to reach [3]. It is a perennial creeper that grows on the ground, covering large areas and improving soil fertility. It bears yellow-green inedible fruits [4]. The plant is said to be highly xerophytic, and thrives in sandy loam, sub-desert soils and sandy sea coasts [5]. This is one of the few native species of plants that grow in the arid conditions of the UAE and other countries of the Middle East and has the potential to be used as a bio-diesel feedstock.

Compared to biodiesel crop Jatropha curcas it has a shorter crop cycle (6 months), can grow in dry desert soils and the oil has lower viscosity [6]. Bio-diesel from Citrullus colocynthis exhibits performance parameters similar to that of bio-diesel from Jatropha when blended with petroleum diesel. The blends also have lower smoke opacity [7]. Up to

Manuscript received February 6, 2014; revised May 22, 2014.

Kiran Menon, Aswathy Preetha Jayakumar, and Neeru Sood are with the Department of Biotechnology, Birla Institute of Technology and Sciences, Dubai Campus (e-mail: p2011003@dubai.bits-pilani.ac.in).

Mohammad Shahid and Nanduri K. Rao are with the International Center for Biosaline Agriculture, Dubai UAE (e-mail: n.rao@biosaline.org.ae).
$30 \%$ of raw oil blend with diesel has been reported to exhibit no change in engine performance and even reduced tail pipe emissions. A $20 \%$ blend however corresponded with optimum engine performance data [8].

In addition to its potential as a bio-diesel feedstock the root and callus extracts of Citrullus colocynthis have been reported to have anti-microbial [9], anti-inflammatory [10], anti- diabetic [11] and anti-oxidant [12] effects. Anti-cancer properties of the fruit have been studied for decades now and in a study as early as 1958, the toxic and potent resinous constituents of the fruit have been seen to cause damage to tumors in mice [13]. The rise of drug resistance and opportunistic infections has lead researchers back to traditional medicines in search of solutions. Extracts of the Citrullus colocynthis plant, which was used in folk medicine in Tunisia was found to have antibacterial and anticandidal properties [14]. In India, in addition to the fruits, root extracts have been indicated for jaundice, ascites, liver problems, rheumatism, fever, urinary disease and stomach pains in traditional medicine [15].

The use of this plant as a bio-indicator of available nutrients $(\mathrm{N}, \mathrm{Ca})$ and contaminating heavy metals $(\mathrm{Cd}, \mathrm{Fe})$ in soil has also been suggested by researchers in Saudi Arabia [16]. These additional characteristics of Citrullus colocynthis adds to the interest in studying its cultivation in the soil and climate conditions of the Middle East. If a medicinal extract can be obtained simultaneously with its use as a bio-diesel feedstock and a contamination and nutrient indicator the commercial viability of its cultivation in this region could be augmented.

Seed dormancy in C. colocynthis, especially in fresh seeds, has been reported in literature [17], [18]. Improving germination efficiency is crucial for the commercial cultivation of any species. The objective of this study is to determine the most effective method to break dormancy and to study the salinity tolerance by in vitro screening of the 30 accessions collected from the UAE.

\section{Methods}

Seven different pre-treatment methods were compared (T1-T7) for their efficacy to overcome fresh seed dormancy. As test control, seeds were placed on $0.8 \%$ agar in petri plates at room temperature without any pre-treatments. It was observed that none of these seeds germinated.

- T1- Manual scarification using sandpaper followed by soaking for 48 hours and incubation at room temperature

- T2- Manual scarification using sandpaper followed by soaking for 48 hours and incubation at $30^{\circ} \mathrm{C}$ (Fig. 1)

- T3- Manual scarification using sandpaper followed by soaking for 48 hours and incubation at $30^{\circ} \mathrm{C}$ in $0.8 \%$ agar 
containing $0.2 \%$ potassium nitrate

- $\quad$ T4- Incubate at $4^{\circ} \mathrm{C}$ for 48 hours, followed by manual scarification using sandpaper and incubation at room temperature

- T5- Manual scarification followed by incubation at $30^{\circ} \mathrm{C}$

- T6- Incubation at $40^{\circ} \mathrm{C}$ for 48 hours and manual scarification using sandpaper followed by incubation at $30{ }^{\circ} \mathrm{C}$

- $\quad$ T7- Soaking for 48 hours followed by incubation at $30^{\circ} \mathrm{C}$

Two replicates each of 10 seeds were tested in each accession. The treated seeds were placed on $0.8 \%$ agar in petri plates and observed daily for germination.

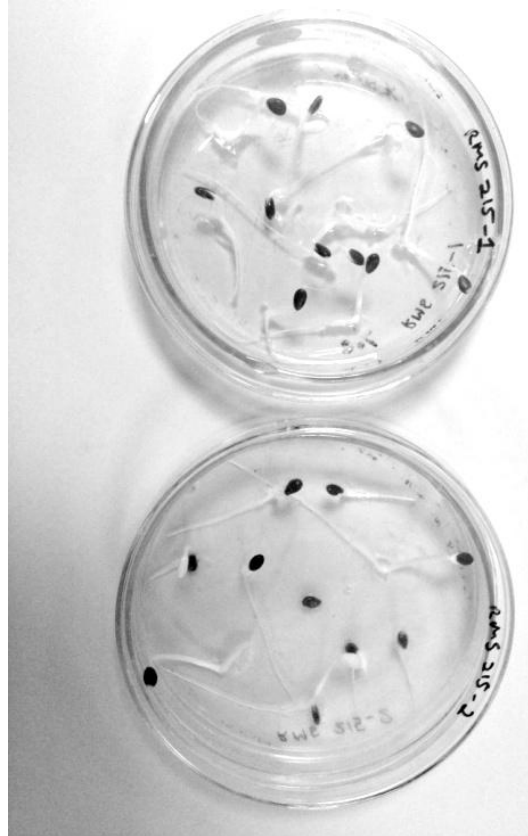

Fig. 1. In vitro germination of seeds on $0.8 \%$ agar after pre-treatment (T2).

Twenty seeds each of the 30 accessions were manually scarified using sandpaper, soaked for 48 hours and incubated on $0.8 \%$ agar at $30{ }^{\circ} \mathrm{C}$ and germination data was observed and recorded daily. This was done in order to identify a smaller number of accessions with high germination efficiency for the salinity screening.

Seeds of 10 accessions were subjected to two different salinity levels with $0.8 \%$ agar medium containing $50 \mathrm{mM}$ $\mathrm{NaCl}$ and $100 \mathrm{mM} \mathrm{NaCl}$ respectively. $0.8 \%$ agar was used as the control treatment. Two petri-plates with 10 seeds each were maintained for each treatment, for all 30 accessions. Germination was recorded daily.

\section{RESUlTS AND DisCUSSION}

Mature fruits of Citrullus colocynthis were collected from 30 different locations in the UAE (Fig. 2). The geographical coordinates, morphological characteristics and features of the plants were recorded.

In all accessions, no germination was observed without any pre-treatment (control). Among the different dormancy breaking treatments studied, manual scarification followed by soaking for 48 hours and incubation at $30{ }^{\circ} \mathrm{C}$ gave the best results, with almost $100 \%$ germination occurring within 48 hours (Table I). Manual scarification or soaking alone did not have the same effect. Neither did scarification and soaking followed by incubation at room temperature. This suggests that seed dormancy in $C$. colocynthis could be attributed to both mechanical and bio-chemical factors. It is possible that the seed contains certain inhibitory factors that need to leach out (for which the seed coat breach and soaking is necessary) in order for germination to occur. The temperature requirement is in keeping with the plants natural environment.

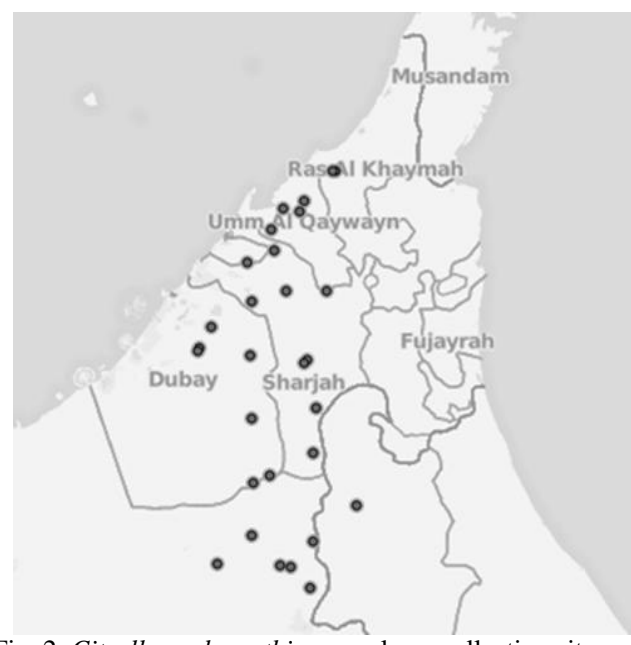

Fig. 2. Citrullus colocynthis germplasm collection sites.

TABLE I: PRE-TREATMENT METHODS AND EFFECT ON GERMINATION

\begin{tabular}{|c|c|c|c|c|c|c|c|c|}
\hline & 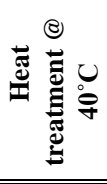 & 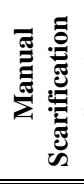 & 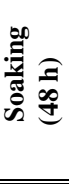 & 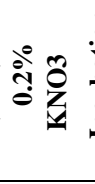 & 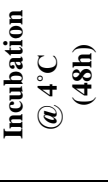 & 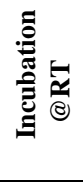 & 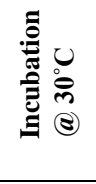 & 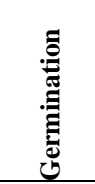 \\
\hline $\mathbf{T} 1$ & & $\mathbf{X}$ & $\mathbf{X}$ & & & $\mathbf{X}$ & & - \\
\hline $\mathbf{T} 2$ & & $\mathbf{X}$ & $\mathbf{X}$ & & & & $\mathbf{X}$ & $\begin{array}{c}\text { Within } \\
48 \mathrm{~h}\end{array}$ \\
\hline T3 & & $\mathbf{X}$ & $\mathbf{X}$ & $\mathbf{X}$ & & & $\mathbf{X}$ & $\begin{array}{c}\text { Within } \\
62 \mathrm{~h}\end{array}$ \\
\hline T4 & & $\mathbf{X}$ & & & $\mathbf{X}$ & $\mathbf{X}$ & & - \\
\hline T5 & & $\mathbf{X}$ & & & & & $\mathbf{X}$ & - \\
\hline T6 & $\mathbf{X}$ & $\mathbf{X}$ & & & & & $\mathbf{X}$ & - \\
\hline T7 & & & $\mathbf{X}$ & & & & & - \\
\hline
\end{tabular}

Of the 30 accessions, germination efficiency varied between 0 and $100 \%$ after pre-treatment. 10 accessions had germination efficiency greater than $80 \%$ in vitro (Fig. 3) These 10 accessions were used for the in vitro salinity trials.

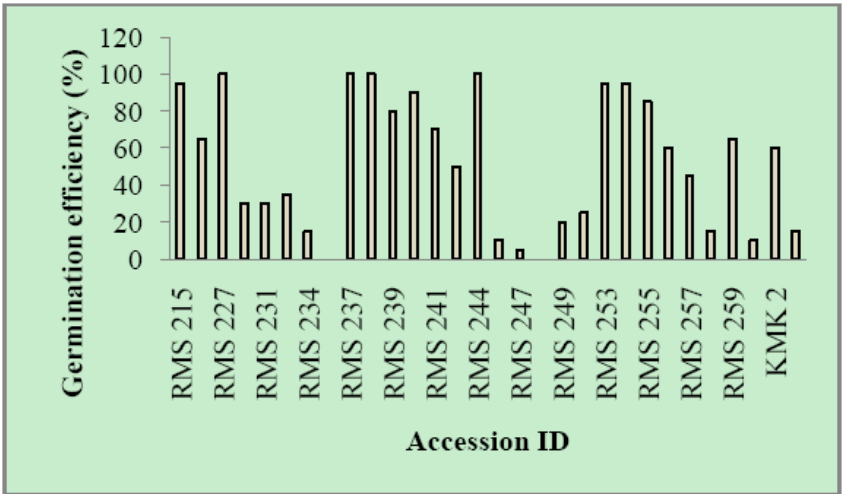

Fig. 3. Germination efficiency of 30 accessions after pre-treatment (T2) 
The in vitro tests for salinity tolerance showed that $C$. colocynthis is highly sensitive to salinity (Fig. 4). At $50 \mathrm{mM}$ $\mathrm{NaCl}$ germination decreases by between 10 and $100 \%$ in comparison with the control, depending on the accession. In the $100 \mathrm{mM} \mathrm{NaCl}$ medium, germination efficiency was very low, between 0 and 5\%. There is a significant variability in salinity response between different genotypes. Considering the overall performance at both salinities, accessions RMS $215,237,244$ and 253 were found to be relatively tolerant and RMS 227 sensitive to salinity. In general however, C.colocynthis appears to be sensitive to salinity, with germination being affected at higher levels of salinity.

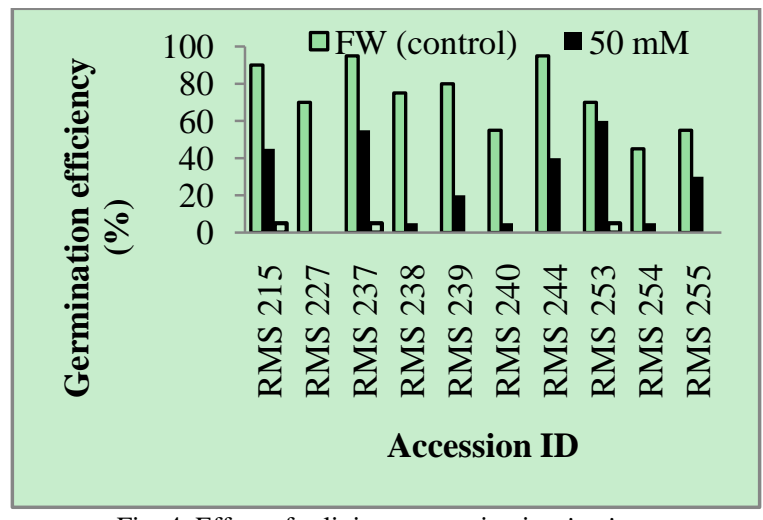

Fig. 4. Effect of salinity on germination in vitro.

Since salinity tolerance/sensitivity varies depending on developmental stage, further studies are necessary under field conditions to assess the effect of salinity on growth performance and yield potential.

\section{CONCLUSION}

In this study an effective pre-treatment was identified to break dormancy in $C$. colocynthis seeds. The identification of the specific biochemical factors involved in the inhibition of seed germination is an area in which analysis is currently underway. C. colocynthis being an exceptionally hardy plant with a potential for use as biodiesel feedstock, the salinity tolerance potential is worth exploring for its economic exploitation through large-scale cultivation in marginal and salt-affected lands. Further investigation is warranted to identify the threshold level beyond which germination and growth are effected, especially under saline growing conditions.

\section{REFERENCES}

[1] M. Achu, E. Fokou, C. Tchiegang, M. Fotso, and F. Tchouanguep, "Nutritive value of some cucrbitaceae oilseeds from different regions in Cameroon," African Journal of Biotechnology, vol. 11, pp. 1329-1334, 2005.

[2] M. Qasim, M. A. Khan, and S. Gulzar, "Halophytes as medicinal plants," presented at NAM Meeting, Denizli, Turkey, 2011.

[3] A. M. Althawadi and J. Grace, "Water use by the desert cucurbit Citrullus colocynthis (L) Schrad.," Oecologia, vol. 70, pp. 475-480, 1986.

[4] Y. Bande, N. Adam, Y. Azmi, and O. Jamarei, "Determination of selected physical properties of Egusi Melon (Citrullus colocynthis lanatus) seeds," Journal of Basic and Applied Sciences, vol. 8, pp. 257-265, 2012.

[5] F. A. Ghamdi, H. A. Zahrani, and K. A. Amer, "Phytosociological studies of Citrullus colocyanthis L., growing in different altitudinal sites in Saudi Arabia," Pakistan Journal of Biological Sciences, vol. 12, no. 10, pp. 779-785, 2009.
[6] A. Pal, S. Kachhwaha, S. Maji, and M. Babu, "Thumba (Citrullus colocyntis) seed oil: A sustainable source of renewable energy for biodiesel production," Journal of Scientific and Industrial Research, vol. 69, pp. 384-389, 2010.

[7] Y. Mathur, M. Poonia, U. Pandel, and R. Singh, "Performanc and emission characteristics of diesel engine using low concentration thumba oil diesel blends," International Journal of Wind and Renewable Energy, vol. 1, no. 2, pp. 108-113, 2012.

[8] E. Bello and A. Makanju, "Performance evaluation of Egunsi melon (Citrullus colocynthis L.) seeds oil biodiesel," Journal of Emerging Trends in Engineering and Applied Sciences, vol. 2, no. 5, pp. 741-745, 2011.

[9] S. Gurudeeban, E. Rajamanickam, T. Ramanathan, and K. Satyavani, "Antimicrobial activity of citrullus colocynthis in Gulf of mannar," International Journal of Current Research, vol. 2, pp. 78-81, 2010.

[10] E. Rajamanickam, S. Gurudeeban, T. Ramanathan, and K. Satyavani, "Evaluation of anti inflammatory activity of Citrullus colocynthis," International Journal of Current Research, vol. 2, pp. 67-69, 2010.

[11] S. Gurudeeban and T. Ramanathan, "Antidiabetic effect of Citrullus colocynthis in alloxon-induced diabetic rats," Inventi Rapid: Ethno pharmacology, vol. 1, p. 112, 2010.

[12] S. Gurudeeban, T. Ramanathan, and K. Satyavani, "Antioxidant and radical scavenging activity of Citrullus colocynthis," Inventi Rapid: Nutracuticlas, vol. 1, p. 38, 2010.

[13] R. E. Faust, G. Cwalina, and E. Ramstad, "The antineoplastic action of chemical fractions of the fruit of citrullus colocynthis on sarcoma-37," J. Pharm. Sci., vol. 47, pp. 1-5, 1958.

[14] B. Marzouk, Z. Marzouk, R. Décor, H. Edziri, E. Haloui, N. Fenina, and M. Aouni, "Antibacterial and anticandidal screening of Tunisian Citrullus colocynthis Schrad. from Medenine," Journal of Ethnopharmacology, vol. 125, no. 2, pp. 344-349, 2009

[15] S. Mohammed, P. Kasera, and J. Shukla, "Unexploited plants of potential medicinal value from the Indian Thar desert," Indian Journal of Natural Products and Resources, vol. 3, no. 2, pp. 69-74, 2004.

[16] N. A. Y. Mohammed, S. Hassan, A. E. S. Mohamed, and M. E. Ebrahem, "Bioaccumulation of nutrient and heavy metals by Calotropis procera and Citrullus colocynthis and their pontential use as contamination indicators," Scientific Research and Essays, vol. 6, no. 4, pp. 966-976, 2011.

[17] K. P. Sahoo and P. K. Kasera, "Biology and in vitro germination behaviour of citrullus colocynthis seeds after pretreatments," The Bioscan, vol. 8, no. 2, pp. 509-511, 2012.

[18] M. Saberi and A. Shahriari, "Comparison of the effect of different treatments for breaking seed dormancy of Citrullus colocynthis," Journal of Agricultural Science, vol. 3, no. 4, 2011.

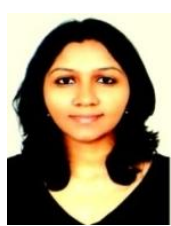

Kiran Menon is a PhD student at the Birla Institute of Technology and Science Pilani, Dubai Campus. She is currently working on her thesis titled 'An assessment of the potential of feedstock crops for Bio-diesel production in the United Arab Emirates.' She obtained her master's degree in biotechnology from Hochschule Mannheim, Germany and her bachelor degree of technology, also in biotechnology from VIT University, Vellore in India. She has broad ranging interests in the field of biotechnology and has previously worked with the Center for Medical Research (ZMF), University of Heidelberg- Medical Faculty of Mannheim in Germany with a research group focused on Polycystic Kidney Disease. To date, she has authored or co-authored 9 publications in International conferences and peer-reviewed journals.

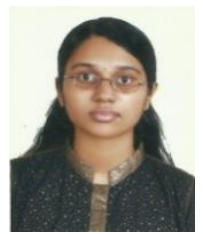

Aswathy Preetha Jayakumar is a final year student of bachelor of engineering in biotechnology at Birla Institute of Technology and Science Pilani, Dubai Campus in the UAE. She is currently doing her thesis on mass production of micro-algae with emphasis on the design and construction of a photobioreactor.

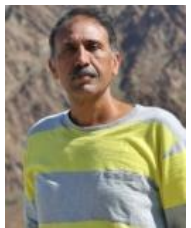

Mohammad Shahid is a scientist with the International Center for Biosaline Agriculture (ICBA), Dubai, UAE $\mathrm{He}$ holds a $\mathrm{PhD}$ degree in genetics from Virginia Tech, USA. He has more than 18 years of experience in agriculture research. He has an expertise in plant breeding, germplasm collection, seed production and screening of salt tolerant crops. He has worked with many crops including, barley, wheat pearl millet, sorghum, sunflower, safflower and others. He had worked on breeding of salicornia, a halophyte, using 
modern molecular markers. He also has done an extensive study of barley and wheat landraces of Arabian Peninsula. Before joining ICBA, he worked as a research officer at Rice Research Institute, Lahore, Pakistan. There he developed experiments and worked to produce high yielding, disease resistant and aromatic rice varieties. He also worked there on the maintenance of local rice germplasm. Based on his research at ICBA, 13 research papers have been published in various science journals.

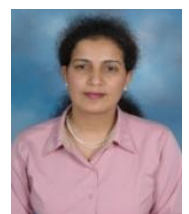

Neeru Sood is an associate professor and the head of Department of Biotechnology BITS Pilani, Dubai Campus. She was involved in designing and development of the course curriculum for B.E (Hons.) Biotechnology, setting up the laboratories for the Biotechnology program She teaches various courses to undergraduate and postgraduate students in biotechnology at Dubai Campus and is involved in institute wide developmental activities. She holds a Ph.D. degree from Punjab Agricultural University Ludhiana, India. She was appointed as a faculty in the Center for Biotechnology, Biological Sciences Group, Birla Institute of Technology and Science, Pilani, Rajasthan in 2000. Before this she worked as a biotechnologist (Plant Tissue Culture) at R\&D Center, Nahar Sugar \& Allied Industries. Ltd. (Oswal group of Companies), Amloh, Punjab. She has more than 40 publications in international, peer-reviewed journals and conferences.

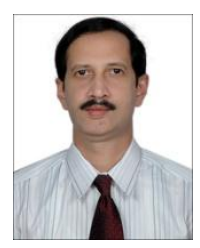

Nanduri Kameswara Rao has been a plant genetic resources scientist with the International Center for Biosaline Agriculture (ICBA), Dubai, leading the genetic resources program since 2006. He obtained his $\mathrm{Ph} . \mathrm{D}$. degree from the University of Reading, UK in seed physiology and has worked as a post-doctoral fellow at the International Rice Research Institute (IRRI), Philippines. He was associated with the International Crops Research Institute for the Semi-arid Tropics (ICRISAT), India, for 25 years (1977-2002) and has held several senior positions, including the head of Genebank. He also worked at the International Plant Genetic Resources Institute (IPGRI), Regional Office for sub-Saharan Africa, Kenya, as a germplasm conservation scientist for 4 years. He has authored or coauthored over 100 publications that include a book on salt-tolerant plants, two technical manuals and an e-learning module on seed genebank operations, many refereed journal articles, conferences papers and research reports. 